\title{
GIS-based Spatial Multi-criteria Analysis: A Vulnerability Assessment Model for the Protected Areas of Vietnam
}

\author{
Quynh Huong Nghiem \\ Department of Geography, University of Greifswald, Germany \\ huong.nghiem@stud.uni-greifswald.de
}

Full paper double blind review

\begin{abstract}
The establishment and management of protected areas has become a universally accepted way to conserve biodiversity, and the wide range of goods and services they offer. Using the environmental vulnerability index (EVI), devised by the South Pacific Applied Geoscience Commission (SOPAC) and the United Nations Environment Program (UNEP) as the theoretical framework, a vulnerability assessment model was developed and used to assess the vulnerability of Bach Ma National Park. The model utilizes spatial multi-criteria decision analysis, combined with a geographic information system (GIS) platform, and can be generalized to assess the vulnerability of other national parks in Vietnam. This paper illustrates the case of Bach Ma National Park in Central Vietnam. The park is threatened by a high loss of biodiversity, particularly through hunting of wildlife for local consumption and trade, the illegal extraction of timber, and the collection of non-timber forest products.
\end{abstract}

Keywords: GIS, Multi-criteria decision analysis, Analytic Hierarchy Process, Vietnam, protected area management, vulnerability assessment

\section{Introduction}

This paper outlines a deductive vulnerability assessment model developed for the case of Bach Ma National Park (BMNP) (Figure 1). In environmental assessment, multiple criteria decision analysis (MCDA) provides strong techniques for defining and structuring problems, as well as evaluating and prioritizing alternatives. The Analytic Hierarchy Process (AHP), developed by SAATY (1987), has been widely applied to various disciplines such as economy, human resource management, land-use planning, risk assessment, and environmental management. Furthermore, Geographic Information Systems (GIS) are well known as spatial decision support systems, which can be used for the analysis, management, and presentation of spatial data. As such, GIS-MCDA is a strong technique for integrating spatial data and value judgments, to gain useful information for making appropriate decisions. 


\section{Protected Areas in Vietnam}

National parks contribute to national well-being, provide resources for education, and deliver economic benefits, both to communities living close by and to the major development sectors. Countries in transition face the challenge of promoting development while presserving national resources. Before the land reform and the introduction of the Doi Moi policy, almost all uplands and forestry lands in Vietnam were under collective or state farm management. However, due to the state's inability to prevent illegal use of forest resources, a considerable amount of land was under open access, with no management regime imposed. In the movement from state to privately managed forests, many policies and programs were created to make significant gains in protection of land cover resources. Generally, however, the problems of forest protection and management still persist, and are aggravated by the rapidly growing population and social-economic transformations.
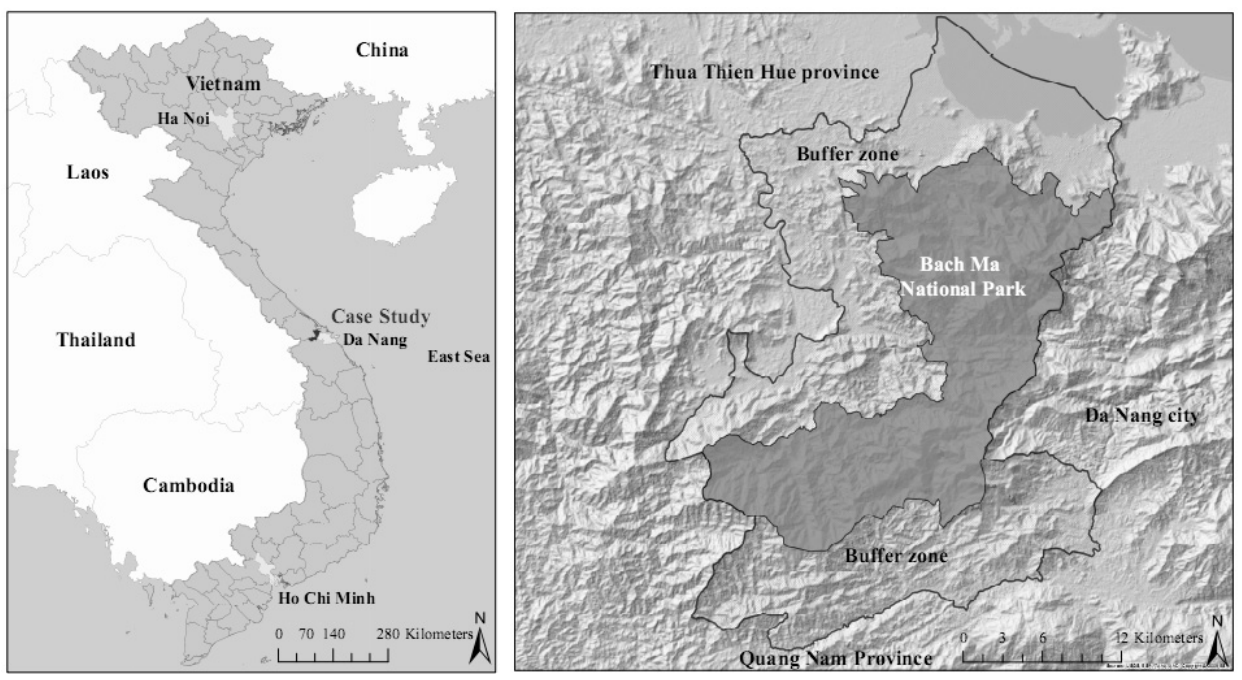

Fig. 1: Case study area - Bach Ma National Park (background: shaded relief map)

\section{Methods and Data Processing}

\subsection{Vulnerability Assessment Methodology}

Vulnerability can be considered as the tendency for an entity to be damaged (Pratt et al. 2004). Vulnerability assessment provides an important guide towards sustainable management. It helps build awareness and prevent risk. Assessing the vulnerability of any system (environment, social and/or economic) therefore not only focuses on risk factors, but also on understanding how adaptive the system is to any stressors or hazards.

Environmental vulnerability is different from vulnerability of anthropogenic systems because the environment is complex, with different levels of organization, from species to interdependent ecosystems, and the complex linkages between them (UNEP 2003, RANNOW et al. 2014). As protected areas naturally contain a variety of species important for 
biodiversity, the vulnerability assessment in this study especially focuses on those species, which are either threatened, and / or regarded as vulnerable in the BMNP's red data list of threatened species. Building upon the environmental vulnerability index (EVI) of the South Pacific Applied Geoscience Commission (SOPAC) (PRATT et al. 2004), the assessment protocol of National Oceanic and Atmospheric Administration (NOAA 1999), and experience in environmental vulnerability research in Vietnam (MAI et al. 2009), the model for vulnerability assessment of the BMNP was developed.

In this study, vulnerability is defined as a function of three components:

$$
\mathrm{Vi}_{\mathrm{j}} \mathrm{j}_{\mathrm{j}}=\mathrm{f}\left(\mathrm{aDx}_{\mathrm{i}} \mathrm{y}_{\mathrm{j}}, \mathrm{bVx}_{\mathrm{i}} \mathrm{y}_{\mathrm{j}}, \mathrm{cAx} \mathrm{x}_{\mathrm{i}} \mathrm{y}_{\mathrm{j}}\right)
$$

In which,

1) $\mathrm{Dx}_{\mathrm{i}} \mathrm{y}_{\mathrm{j}}$ : driving forces - the hazards that directly impact the BMNP.

2) $V_{x_{i}} y_{j}$ : vulnerable objects - spatial density and distribution of vulnerable objects (population, properties, resources, ecosystems ...).

3) $\mathrm{Ax}_{\mathrm{i}} \mathrm{y}_{\mathrm{j}}$ : adaptive capacity - objects, which increase or decrease adaptive capacity; $\mathrm{x}_{\mathrm{i}} \mathrm{y}_{\mathrm{j}}$ represent the coordinate system, and a, b, c are the weights of the components.

\subsection{AHP Approach}

An expert interview-based vulnerability methodology is a very strong tool for collecting and analysing vulnerability, for conducting an effective and context-specific vulnerability assessment. Following previous GIS integration uses, the AHP was chosen to prioritise the GIS information (BOTTERO et al. 2013).

The Analytic Hierarchy Process (AHP) is a multi-criteria decision method that uses hierarchical structures through pairwise comparisons to present a problem, and then develop priority scales based on judgements of experts. Problems are broken down into their smaller and smaller constituent parts, and then decision makers are guided through a series of pairwise comparison judgments to express the relative intensity of impact of elements in the hierarchy (SAATY \& KEARNS 1991). The expert makes pairwise comparisons between the different criteria to obtain these values of weights. When he/she compares a set of criteria with each other, a square matrix is produced, and has reciprocal properties.

In practice, a perfect consistency in measurement is difficult to attain. However, we have measures to assess the extent of deviation from consistency.

The consistency index $(C I)$ for each matrix can be calculated by formula:

$$
C I=\frac{\lambda_{\text {max }}-n}{n-1}
$$

where $\mathrm{n}$ is number of criteria being compared. For a reciprocal matrix, $\lambda_{\max } \geq n$.

If we divide the $C I$ by the random consistency number for the same size matrix, then we obtain the consistency ratio $(C R)$ :

$$
C R=\frac{C I}{R I}
$$

where $R I$ is the average value of $C I$ values for random matrices using the Saaty scale (Table 1). 
Table 1: The average consistencies for different order random matrices (SAATY 1980)

\begin{tabular}{|l|l|l|l|l|l|l|l|l|l|l|}
\hline Size of matrix & $\mathbf{1}$ & $\mathbf{2}$ & $\mathbf{3}$ & $\mathbf{4}$ & $\mathbf{5}$ & $\mathbf{6}$ & $\mathbf{7}$ & $\mathbf{8}$ & $\mathbf{9}$ & $\mathbf{1 0}$ \\
\hline RI & 0.00 & 0.00 & 0.58 & 0.90 & 1.12 & 1.24 & 1.32 & 1.41 & 1.45 & 1.49 \\
\hline
\end{tabular}

$\mathrm{CR}$ indicates the amount of allowed inconsistency. Higher $\mathrm{CR}$ means that the comparisons are less consistent. Smaller CR means comparisons are more consistent. $\mathrm{CR}=0$ means that the result is perfectly consistent. If $C R \leq 0.1(10 \%)$, then the results are consistent and we can obtain the final overall rating (Saaty 1980).

Based on SAATY (1980), to make an AHP decision, we first need to define the problem, as well as the need and purpose of the decision, and establish criteria and their sub-criteria to generate alternatives. After that, an AHP hierarchy is developed by constructing pairwise comparison matrices, calculating eigenvalue $\lambda_{\max }$, eigenvector $\omega$, consistency index (CI), and consistency ratio (CR).

A scale from 1 to 9 is used to determine the relative preferences between two elements in the hierarchy in matrix A (SAATY 1990) (see Table 2).

Table 2: Fundamental scale of absolute numbers ranging from 1 to 9

\begin{tabular}{|c|c|c|}
\hline $\begin{array}{l}\text { Intensity of } \\
\text { importance }\end{array}$ & Definition & Explanation \\
\hline 1 & Equal importance & Two activities contribute equally to the objective \\
\hline 2 & Weak & \\
\hline 3 & Moderate importance & $\begin{array}{l}\text { Experience and judgment slightly favor one activ- } \\
\text { ity over another }\end{array}$ \\
\hline 4 & Moderate plus & \\
\hline 5 & Strong importance & $\begin{array}{l}\text { Experience and judgment strongly favor one } \\
\text { activity over another }\end{array}$ \\
\hline 6 & Strong plus & \\
\hline 7 & $\begin{array}{l}\text { Very strong demonstrated } \\
\text { importance }\end{array}$ & $\begin{array}{l}\text { An activity is favored very strongly over another; } \\
\text { its dominance demonstrated in practice }\end{array}$ \\
\hline 8 & Very, very strong & \\
\hline 9 & Extreme importance & $\begin{array}{l}\text { The evidence favoring one activity over another is } \\
\text { of the highest possible order of affirmation }\end{array}$ \\
\hline
\end{tabular}

Aggregation judgment matrices of the group experts are calculated by:

$$
\mathrm{A}_{\mathrm{ij}}=\left(\prod_{k=1}^{n} a_{i j k}\right)^{1 / n}
$$


Nine experts involved with the management of BMNP were chosen from a range of disciplines and backgrounds (see Table 3).

Table 3: Expert interviewed for this study

\begin{tabular}{|l|l|l|}
\hline Expert & Job Position & Specialist \\
\hline 1 & $\begin{array}{l}\text { Director of the BMNP and leader of BM Forest Pro- } \\
\text { tection Section }\end{array}$ & Biology \\
\hline 2,3 & Vice-Directors of the BMNP & Forestry and agriculture \\
\hline 4 & Deputy chief of BM Forest Protection Section & Law \\
\hline $5,6,7$ & Three official scientific experts in BMNP & Forestry \\
\hline 8 & $\begin{array}{l}\text { Dean of Land resources and agriculture Environ- } \\
\text { mental Faculty in Hue University of Agriculture and } \\
\text { Forestry }\end{array}$ & $\begin{array}{l}\text { Land-use and agriculture } \\
\text { environment }\end{array}$ \\
\hline 9 & $\begin{array}{l}\text { Teacher of Land resources and agriculture Environ- } \\
\text { mental Faculty in Hue University of Agriculture and } \\
\text { Forestry }\end{array}$ & Agriculture and forestry \\
\hline
\end{tabular}

Questionnaires were pre-tested with experts from BMPN. The data from each expert interview was analyzed in detail, and a pairwise comparison matrix was applied to calculate eigenvalue $\lambda_{\max }$, eigenvector $\omega$, and consistency ratio (CR). Finally, aggregation of all nine judgments was calculated using the geometric mean method.

\subsection{GIS-AHP Integration}

Parameters that reflect vulnerability are very important to be determined and selected. After selecting all suitable parameters, they are aggregated according to appropriate weightings. Such combinations of all the information have been greatly aided by the introduction of GIS capabilities and the integrated spatial multi-criteria approach. With these techniques, storing multidisciplinary data and examining the interrelationships can be digitally performed at various scales (BURROUGH \& MCDONNELL 1986).

Figure 2 shows the overall approach used in this study. For handling geographic information, all of necessary spatial databases were selected, for example, the spatial datasets on threatened species distribution within BMNP. Next, expert interviews were carried out in order to assign weight to the criteria for the AHP process. A map layer was created to represent each criterion and all of those criteria layers were then weighted based on the result of weighting criteria in the AHP process, and using the weighted map algebra tool in GIS. All of the criteria layers were then aggregated and overlaid to produce the final spatially explicit mapped results. 


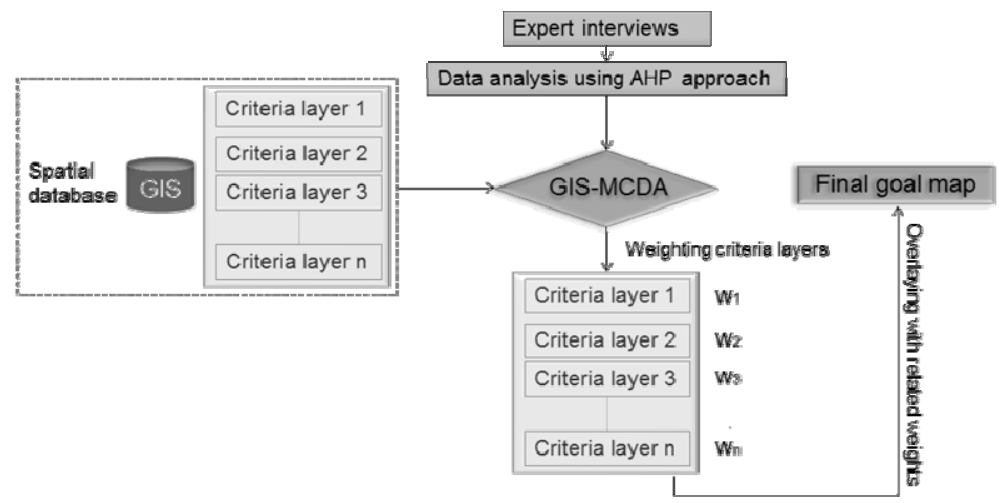

Fig. 2: GIS based Multi-criteria Decision Analysis (MCDA) Approach

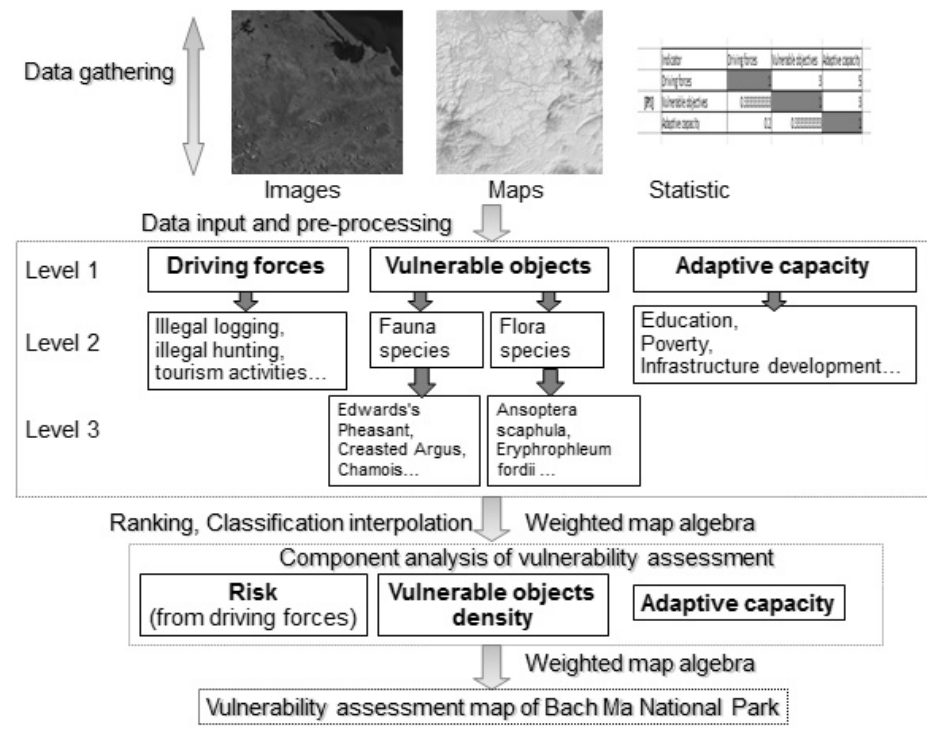

Fig. 3: Applying GIS to create the model of assessing vulnerability for BMNP

Figure 3, shows in detail the vulnerability decision model obtained from combining GIS with AHP to create the weighted map of all assessed components of vulnerability for BMNP. Firstly, spatial data were selected, including digital maps and satellite imagery (ASTER GDEM). Three hierarchical levels of vulnerability assessment for BMNP were developed. The first level consisted of three components: driving forces, vulnerable objects, and adaptive capability. Level 2 was subdivided into different subjects based on 3 related components in level 1. Driving forces were divided into main characteristics such as illegal activities (logging, hunting), or negative impact from tourism activities. To assess the BMNP vulnerability, the research has a special focus on vulnerable fauna and flora species in the area, and is located in level 2 of the model. The adaptive capability of BMNP was also divided into sub-levels in level 2 (such as education, poverty). The third level of the model analysed in detail five different kinds of fauna and five different kinds of flora as 
vulnerable objects. All of those three levels with spatial data were classified and analyzed and overlaid with related weighted maps by using a Python syntax in the raster calculatorinterface.

\section{Results}

The results of AHP, analysing the driving forces of risk, showed that illegal activities in the BMNP constitute the main risk - totaling $73 \%$ of all risk. Here, illegal logging makes up about $44 \%$, and illegal hunting composes about $29 \%$ of the total risk (see Table 4 ).

Table 4: Hierarchical structure and weighted results of pairwise comparison sessions

\begin{tabular}{|c|c|c|}
\hline $\begin{array}{l}\text { Group criteria } \\
\text { (Level 1) }\end{array}$ & $\begin{array}{l}\text { Criteria } \\
\text { (Level 2) }\end{array}$ & $\begin{array}{l}\text { Sub-criteria } \\
\text { (Level 3) }\end{array}$ \\
\hline \multirow{5}{*}{$\begin{array}{l}\text { Driving forces } \\
(0.555)\end{array}$} & Erosion $(0.073)$ & \\
\hline & Waterways (0.061) & \\
\hline & Negative impact from tourism $(0.131)$ & \\
\hline & Illegal logging $(0.443)$ & \\
\hline & Illegal hunting $(0.292)$ & \\
\hline \multirow{10}{*}{$\begin{array}{l}\text { Vulnerable objects } \\
(0.256)\end{array}$} & \multirow{5}{*}{ Fauna $(0.50)$} & Lophura edwardsi (0.096) \\
\hline & & Rheinardia ocellata $(0.150)$ \\
\hline & & Rupicapra rupicapra (0.349) \\
\hline & & Macaca nemestrina (0.215) \\
\hline & & Ursus thibetanus $(0.190)$ \\
\hline & \multirow{5}{*}{ Flora $(0.50)$} & Anisoptera scaphula $(0.465)$ \\
\hline & & Erythrophleum fordii (0.302) \\
\hline & & Sterculia lychnophora $(0.121)$ \\
\hline & & Podocarpus annamiensis $(0.055)$ \\
\hline & & Nageia fleuryi (0.057) \\
\hline \multirow{6}{*}{$\begin{array}{l}\text { Adaptive capacity } \\
(0.189)\end{array}$} & Waterways (0.051) & \\
\hline & Local people $(0.091)$ & \\
\hline & Education $(0.214)$ & \\
\hline & Poverty $(0.288)$ & \\
\hline & Management (0.255) & \\
\hline & Infrastructure development $(0.101)$ & \\
\hline
\end{tabular}


In regards to the adaptive capacity of the BMNP, the results showed that both the poverty of the people in the buffer zone, and the management capacity of stakeholders in the BMNP, play an important role. The analysis showed that the state of poverty occupies about $29 \%$, and the management capacity occupies about $26 \%$ of the total impact regarding the adaptive capacity of the BMNP (see Table 4).

Five vulnerable fauna, including: Lophura edwardsi, Rheinardia ocellata, Rupicapra rupicapra, Macaca nemestrina, and Ursus thibetanus; and five vulnerable floras, including: Anisoptera scaphula, Erythrophleum fordii, Sterculia lychnophora, Podocarpus annamiensis, Nageia fleuryi were analysed in detail. The results showed that the identified most vulnerable fauna was Rupicapra rupicapra, while Ansoptera scaphula is the most vulnerable flora.

Based on these weighting results, the spatial distribution of vulnerable objects for the ten different species was mapped to provide the weighted spatial distribution of vulnerable objects. Spatial analysis tools such as density, distance, classification, and weighted map algebra were mainly used for analysing spatial multi-criteria in the study.

Figure 4 shows the vulnerable fauna and flora overlaid to display the density of endangered and precious species in the BMNP, and also in the Red List data of Vietnam. The color in the Figure changes from light green - which represents very low vulnerability object areas, to yellow - which represents medium vulnerability object areas, and finally to red - which represents high vulnerability object areas.

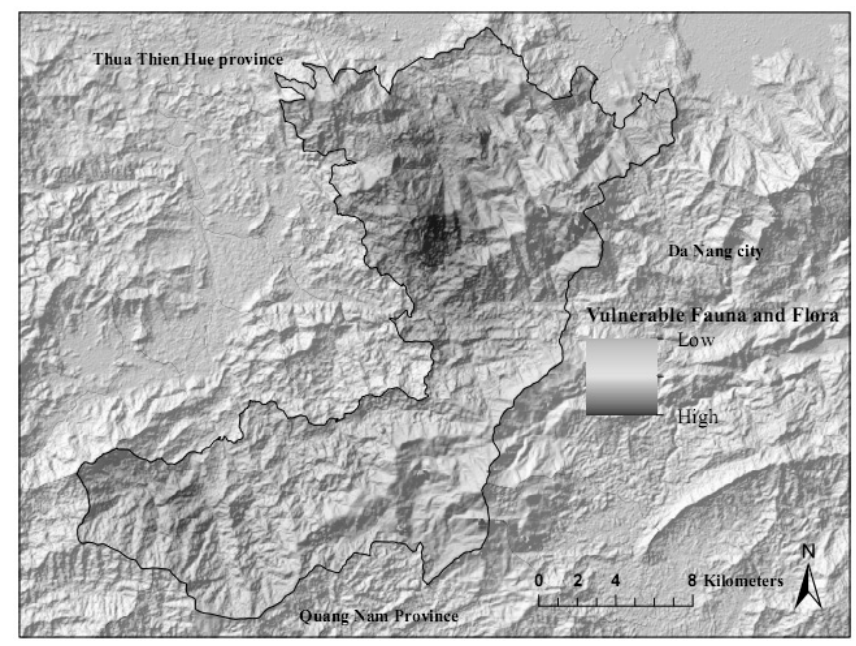

Fig. 4: Weighted spatial distributions of 10 main vulnerable species in the BMNP

\section{Conclusion and Discussion}

This paper highlights the initial results from a study aimed at producing a high-precision geo-database, which is very helpful for sustainably managing the BMNP. This helps stake- 
holders identify suitable actions to focus on the most important species, and ecosystems that are most vulnerable, and in the most important areas, which have the highest vulnerability. The main contribution of this study is the development of a vulnerability assessment model using a spatial multi-criteria approach, integrating both GIS and AHP.

However, not all collected data could be represented spatially in GIS. For example, not all of the fauna and flora of the National Park could be assessed for vulnerability; this was mainly due to a lack of statistical information and spatial data. As such, the vulnerable objects, which were assessed in this research, are purely a selection of the endangered and precious vulnerable fauna and flora to be found within the BMNP. Therefore, the vulnerability map is limited in that it does not show the entire spatial distribution of all vulnerable objects in the BMNP, but solely focuses on the 5 most vulnerable flora and the 5 most vulnerable fauna species.

\section{References}

Bottero, M., Comino, E., Duriavig, M., Ferretti, V. \& Pomarico, S. (2013), The application of a Multicriteria Spatial Decision Support System (MCSDSS) for the assessment of biodiversity conservation in the Province of Varese (Italy). Land Use Policy, 30 (1), 730-738. DOI:10.1016/j.landusepol.2012.05.015.

Burrough, P. A \& MCDonnell, R. (1986), Principles of Geographical Information Systems for Land Resource Assessment, Clarendon Press, New York.

Kaly, U., Pratt, C. \& Mitchell, J. (2004), The Environmental Vulnerability Index (EVI). SOPAC.

Mai, T. N., Nguyen, T. M. N., Nghiem, Q. H., Nguyen, T. H. H., Nguyen, T. T. \& Pham B. N. (2009), Assessment of Vietnam Coastal Wetland Vulnerability for Sustainable Use (Case Study in Xuanthuy Ramsar Site, Vietnam). Journal of Wetlands Ecology, Nepal, 2/2009, 1-16. DOI:10.3126/jowe.v2i1.1850.

National Oceanic and Atmospheric Administration - NOAA (1999), Community vulnerability assessment tool. CD-ROM. NOAA Coastal Services Center.

Pratt, C., KAly, U. \& Mitchell, J. (2004), Manual: How to use the environmental vulnerability index (EVI). SOPAC Technical Report 383. United Nation Environment Programme (UNEP). South Pacific Applied Geoscience Commission (SOPAC).

Rannow, S., Macgregor, N. A., Albrecht, J., Crick, H. Q. P., Förster, M., Heiland, S., Janauer, G., Morecroft, M. D., Neubert, M., Sarbu, A. \& Sienkiewicz, J. (2014), Managing Protected Areas Under Climate Change: Challenges and Priorities. Environmental Management, 54, 732-743. DOI:10.1007/s00267-014-0271-5.

SAATY, T. L. (1980), Multi-criteria Decision Making: The Analytic Hierarchy Process. McGraw-Hill, New York, $2^{\text {nd }}$ printing 1990, RSW Pub. Pittsburgh.

SAATY, T. L. (1987), The Analytic Hierarchy Process - What it is and how it is used. Mathl Modelling, 9 (3-5), 161-176. DOI:10.1016/0270-0255(87)90473-8.

SAATY, T. L. (1990), How to make a decision: The analytic hierarchy process. In: Decision making by the analytic hierarchy process: Theory and applications, 48 (1), 9-26. DOI:10.1016/0377-2217(90)90057-I.

SAaty, T. L. \& KEARnS, K. P. (1991), Analytical Planning: The Organization of Systems. The Analytic Hierarchy Process series, Vol. IV, RSW Pub. Pittsburgh. 
United Nation Environment Program (UNEP) - Division of Early Warning Assessment, (2003), Assessing Human Vulnerability to Environmental Change. Concepts, Issues, Methods and Case Studies.

VILLA, F. \& MCLEOD, H. (2002), Environmental Vulnerability Indicators for Environmental Planning and Decision-Making: Guidelines and Applications. Environmental Management, 29 (3), 335-348. DOI:10.1007/s00267-001-0030-2. 